\title{
Investigación \\ La arquitectura más allá de las ciudades. Presente y futuros
}

Ramón Pico Valimaña

Escuela Técnica Superior de Arquitectura. Universidad de Sevilla

\section{Resumen}

Con la revalorización de lo rural, se ha recuperado el interés por el estudio de los pueblos de colonización, incrementándose las acciones de documentación y preservación de los poblados, percibidos como patrimonio colectivo y como espacio representativo de valores opuestos a lo urbano. En este sentido, Ramón Pico defiende en su artículo la importancia social que han cobrado los pueblos de colonización para la ordenación del territorio, entendidos como fórmulas alternativas de desarrollo territorial que frene el crecimiento urbano descontrolado. Sin embargo, el autor cuestiona los prejuicios que aún perduran en torno a las nociones patrimoniales que obstaculizan la labor de conservación de estas poblaciones, preservación que necesita del apoyo institucional y la puesta en marcha de políticas de gestión territorial que apuesten por esta vía de desarrollo.

\section{Palabras clave}

\section{Arquitectura}

Colonización agraria

Instituto Nacional de Colonización

Pueblos de Colonización

Ordenación del territorio

Urbanismo

Viviendas rurales
He corrido las tierras de España y aprendi en sus rincones lo que una arquitectura anónima me enseñaba. Se me llenaban los ojos con eso que el hombre hace para sí, con la sabiduría de su necesidad amparada por la tradición del lugar. De sorpresa en sorpresa adiviné la medida y la función de los espacios que edificó para cobijar su vida y su trabajo, y cómo presentía con respeto los entornos para la convivencia. Así nacían, así se hicieron los pueblos que yo admiraba y de los que aprendi la ley oculta de su ordenación espontánea.

(J.A. Fernández del Amo)

La reivindicación de la condición múltiple del fenómeno urbano a la que asistimos en los últimos años, perfectamente reflejada en las reflexiones de Ignasi Sola-Morales ${ }^{1}$, ha dado paso a una fértil corriente de investigaciones, estudios y publicaciones que han tratado de asentar el conocimiento y que tienen un magnífico remate en las doce capas superpuestas que integran la renovada visión urbana de García Vázquez².

Ahora bien, más allá de lo urbano, del fenómeno metropolitano y la explosión de la ciudad genérica tardocapitalista que tanto nos fascina, parece que el momento resulta adecuado para poner también los ojos en esos otros territorios alejados de las virtudes (y los problemas) de lo urbano.

La etimología del término agroi no deja lugar a dudas: salvaje. Los griegos atribuian todas las virtudes a la vida en la ciudad, el civismo, la finura, el entendimiento, y todas las miserias a la vida agraria, la zafiedad, la torpeza, el mal gusto. Ésta es una condición que lo rural ha arrastrado hasta nuestros dias, pero efectivamente, las condiciones han cambiado ${ }^{3}$. Cambiaron en 1984 y lo siguen haciendo día a día.

Por todo ello, la esperanza desde la que hace algunos años me acerqué por primera vez al estudio de los Poblados de Colonización ${ }^{4}$ hoy se mantiene viva, aunque en una dirección bien distinta que me lleva a comenzar este artículo desde su conclusión: los Poblados de Colonización franquistas cuentan en la actualidad con un altísimo potencial en nuestra sociedad, y más en concreto en el futuro desarrollo territorial de nuestra comunidad andaluza.

\section{Olvidos y maltratos}

El balance actual para los Poblados de Colonización, considerados desde una perspectiva patrimonial, es sin duda negativo a efectos de investigación, protección, conservación y, por supuesto, de intervenciones de recuperación.

Sin duda los poblados han sido, como tantos otros campos del patrimonio, objeto de una evidente discriminación en la que confluian su condición "contemporánea" y la pesada carga ideológica que su 
${ }^{1}$ SOLÁ MORALES, I., COSTA, X. Presente y Futuros. Arquitectura en la grandes ciudades, Col.legi Oficial d'Arquitectes de Catalunya/Centre de Cultura Cotemporània de Barcelona, Barcelona, 1996

${ }^{2}$ GARCIA VÁZQUEZ, C. Ciudad Hojaldre. Barcelona: Gustavo Gili, 2004

${ }^{3}$ SECCHI, B. Le condizioni sono cambiate. Milano: Casabella, 1984
${ }^{4}$ PICO VAlimañA, R. Los Poblados de Colonización. Una Oportunidad para el acuerdo. En Actas del $1^{\mathrm{er}}$ Seminario DoCoMoMo Ibérico, Zaragoza, 1997. Para la ocasión, y junto al equipo, compuesto por alumnos de la ETSA de Sevilla -Daniel Guerrero Oliva, Cristina López-Lago González, José Esteban Martin Mañés, Gema Ortiz Mesa, Carolina Palacio Jiménez, Manuel Plazuelo Caballero y Alvaro Sánchez Palma-, y armados de dos rudimentarios portátiles y un escáner de negativos nos desplazamos a los archivos de Paseo de La Habana dispuestos a digitalizar las microfichas que atesoraban la planimetría original de los poblados andaluces. Desbordados por el trabajo, volveríamos a Sevilla con una base de datos que incluía los datos básicos de los poblados andaluces y las imágenes digitales de 193 microfichas correspondientes a 12 poblados. Actualmente se encuentran en el IAPH.

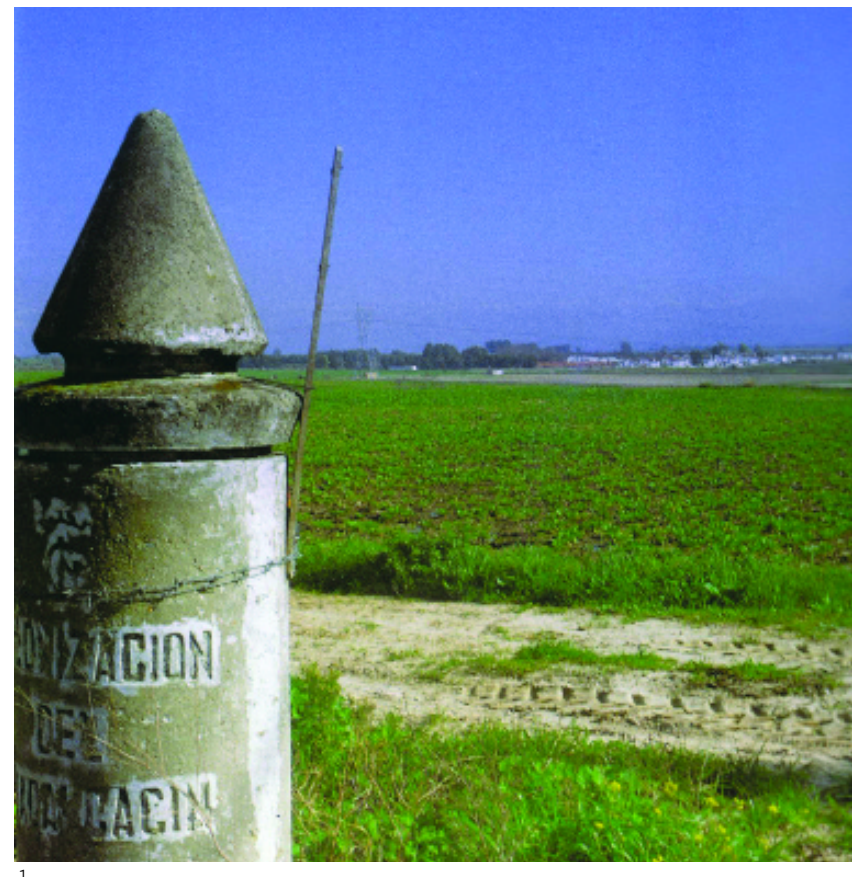

edificar nuevas viviendas. Cuando esto ha ocurrido, desde las Normas Subsidiarias que ordenan el municipio se ha atentado directamente contra la integridad de la ordenación original.

La singular ordenación de Miraelrío tiene su principal valor en el vacio central que la ordena. Fernández del Amo se permitió este trazado gracias al reducido número de viviendas que lo constituian (un total de 60 viviendas entre colonos, obreros y artesanos) y la ubicación del mismo coronando una colina en las proximidades del río. La opción fue radical: ocupando la parte superior de la colina, Del Amo trazó un anillo de viviendas que dejaba en su interior un amplio espacio libre en el que se desarrollan las actividades de la vida comunitaria.

La viviendas construyen la parcela de forma que las dependencias agrícolas 'miran al río' y a las tierras de labor mientras que las zonas vivideras se centran en el espacio público, donde se sitúan la iglesia y el centro cívico, el verdadero corazón del cuerpo cívico.

Justamente en ese corazón mimado por Del Amo se plantea hoy el posible crecimiento del poblado desde un planeamiento que cuenta con los beneplácitos de todas las administraciones interesadas.

En otras ocasiones, la potencia y el desarrollo de la zona ha sido tan arrollador que el poblado ha sido "abducido" por el resto de la estructura urbana, pasando a convertirse en una barriada más. Un ejemplo podriamos encontrarlo en Campohermoso (Nijar, Almeria), 


\section{Investigación \\ La arquitectura más allá \\ de las ciudades. \\ Presente y futuros \\ Ramón Pico Valimaña}

una ordenación en la que Del Amo acudió a la habitual ortogonalidad del trazado como clave de definición de la estructura urbana, trazando parcelas rectangulares en las que la edificación recurre a una patente simplificación formal para acercase a la cúbica arquitectura autóctona. El tipo, meticulosamente elaborado, valoraba también la incorporación de elementos funcionales del lugar como las azoteas visitables o los porches de entrada. El espacio público central es un salón en el que se dispone la iglesia, con un sólido campanario que se vuelve permeable en su basamento en un ejercicio no exento de inquietud. Junto a ella se sitúan los discretos locales municipales, que no ensombrecen la fuerza simbólica de ésta.

Hoy el poblado original es una burbuja de capa dura que gracias a la potencia de su ordenación original mantiene su fisionomía como barrio autónomo dentro de una realidad urbana de mayor y distinta entidad. A este hecho contribuye, sin duda, que la mayoría de sus habitantes sean inmigrantes vinculados a las actividades agricolas de la zona, sobre cuya condición de aislamientos pocas voces insisten.

No siempre ha sido necesaria la cercanía a la ciudad ni el desarrollo de la agricultura para provocar importantes mutaciones. En muchos poblados, el devenir de los acontecimientos y la bonanza de sus economías por otros caminos han ido alterando de una u otra forma su morfología y tipología arquitectónica hasta casos, como San José del Valle (Jerez de la Frontera, Cádiz), en que resultan difícilmente reconocibles sus condiciones originales. En este camino se encuentra el Poblado de Esquivel (Alcalá del Río, Sevilla).

En palabras de De la Sota, Esquivel es un "ensayo transitorio (trazado rígido, detalles amoldados). El trazado es rígido porque nació de una sola vez, de un solo golpe y sobre un terreno llano como la palma de la mano, sin accidente alguno, con orientación simétrica respecto a la carretera, $y$, en estos casos, hace falta ser muy barroco para hacer retorcidos".

Con el recurso a la supermanzana y la segregación de las circulaciones, Sota se enfrenta a un poblado que comienza ya a rebasar los límites de lo definido como aldea. Junto al microespacio del callejero interior, el pueblo se definirá mediante la creación de un macroespacio de representación que ofrece su imagen a la carretera que lo roza tangencialmente. Un espacio escaparate que queda configurado por el borde de la edificación en dos plantas y unos soportales inferiores y la ubicación en el mismo de los edificios representativos: iglesia y ayuntamiento.

En este caso, la estructura urbana proyectada permitía una cómoda ampliación, por lo que el planeamiento urbanístico posterior lo tenía bastante difícil para provocar una debacle del orden de la comentada en Miraelrío. Sin embargo, en Esquivel, el gran problema para la conservación del poblado se encuentra en las importantes alteraciones que en la tipología arquitectónica y en la imagen de las viviendas se viene produciendo, especialmente desde 1992.

No hubo que esperar a un espectacular desarrollo de la agricultura (que nunca llegó) para transformar el caserío. El boom inmobiliario y la reorientación de gran parte de la población masculina hacia el sector de la construcción han propiciado sin duda la mejora del nivel de vida de los habitantes de Esquivel, que empiezan a sentirse incómodos con la imagen "de pueblo" que Sota se esforzó en dar al poblado. El mármol, el gres, la azulejería, los balaustres y aplacados de Leroy Merlin, y la ausencia de disciplina urbanística harian el resto.

\section{Ávidos de naturaleza}

Desarrollo sostenible es aquel modelo de desarrollo que satisface las necesidades de la generación presente sin comprometer la capacidad de las generaciones futuras para satisfacer sus propias necesidades.... y que requiere de un proceso de cambios en el que la utilización de los recursos, la dirección de las inversiones y la orientación de los cambios tecnológicos e institucionales acrecienten en potencial actual y futuro para atender las necesidades y aspiraciones humanas.

(Informe Brundtland, Naciones Unidas, 1987)

Nuestra sociedad está ávida de naturaleza. El marco de la sostenibilidad envuelve hoy prácticamente todas las facetas de la actividad humana, tras convertirse en una positiva obsesión de final de siglo. Su hito de inicio, el Informe Brundtland, ponía inmediatamente el dedo en la llaga: las áreas urbanas son las principales responsables de los problemas medioambientales del planeta (del $75 \%$ de la contaminación y el $70 \%$ del gasto energético actual), luego parece obvio que estos problemas deban resolverse desde ellas.

Se trata de una preocupación habitual en la historia del urbanismo. Vitrubio aportaba a aquéllos que tenían en sus manos el diseño de nuevos asentamientos humanos recomendaciones en torno a cuestiones de emplazamiento, orientación, iluminación natural, etc. En el industrializado siglo XIX, los graves problemas de insalubridad urbana condujeron a un desarrollo de la tendencia higienista: Howard, Cerdá, las City Beautiful. Ya en el siglo XX, el Movimiento Moderno, desde su radical defensa del papel social de la arquitectura y el urbanismo, concebía las zonas verdes como una de las imprescindibles funciones que debía proporcionar la ciudad para el bienestar de sus habitantes.

Todos estos planteamientos entendian sin embargo a la naturaleza como un bien protegido pero susceptible de apropiación por el 
2. Planta de ordenación del Poblado de Miraelrio (Vilches, Jaén). J.A. Fernández del Amo, 1964-67. Fuente: Archivo del INC

3. Miraelrío. Viviendas de colonos del anillo perimetral. Fuente: Archivo del INC

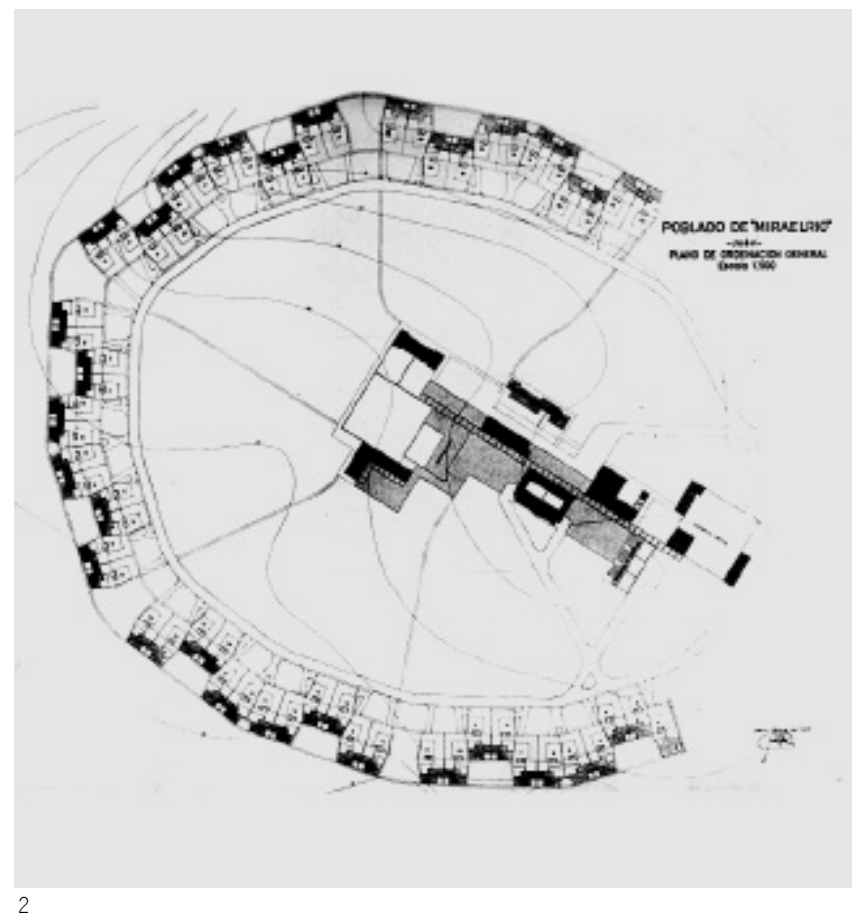

hombre y utilizado por sus efectos para la salud física y mental. Se carecia de una reflexión sobre el agotamiento de los recursos, algo que llegaría en los años cincuenta, con los inicios serios de la investigación sobre fuentes energéticas. Desde entonces se han alternado las de conciencia ambiental (normalmente unidas a crisis de confianza), apagadas a golpes de desarrollismo positivista.

Hoy sin embargo parece que hemos alcanzado un cierto grado de madurez en este sentido y, pese a encontrarnos en un periodo que no se caracteriza especialmente por su falta de optimismo, en el que se nos vende una sociedad en la que todo "va bien", la conciencia ambiental ha calado hondo en todos los niveles.

En el urbanismo actual esta sensibilidad se traduce en la necesidad de estimular un nuevo acercamiento entre arquitectura y naturaleza, favorecido por el paso de una generación obsesionada por la relación entre arquitectura y ciudad a otra más interesada por un nuevo contrato con la naturaleza.

Para Solá-Morales, el entendimiento del fenómeno urbano pasa por reconocer los rasgos y procesos del nuevo mundo: “...en la actualidad, los rasgos y procesos propios de este nuevo mundo urbano son demasiado evidentes como para volver el rostro a un lado y negarles la carta de, nunca mejor dicho, ciudadanía. Se trata de técnicas y procesos que ya existen, con los que se opera, que constituyen prácticas si se quiere ciegas, fragmenta-

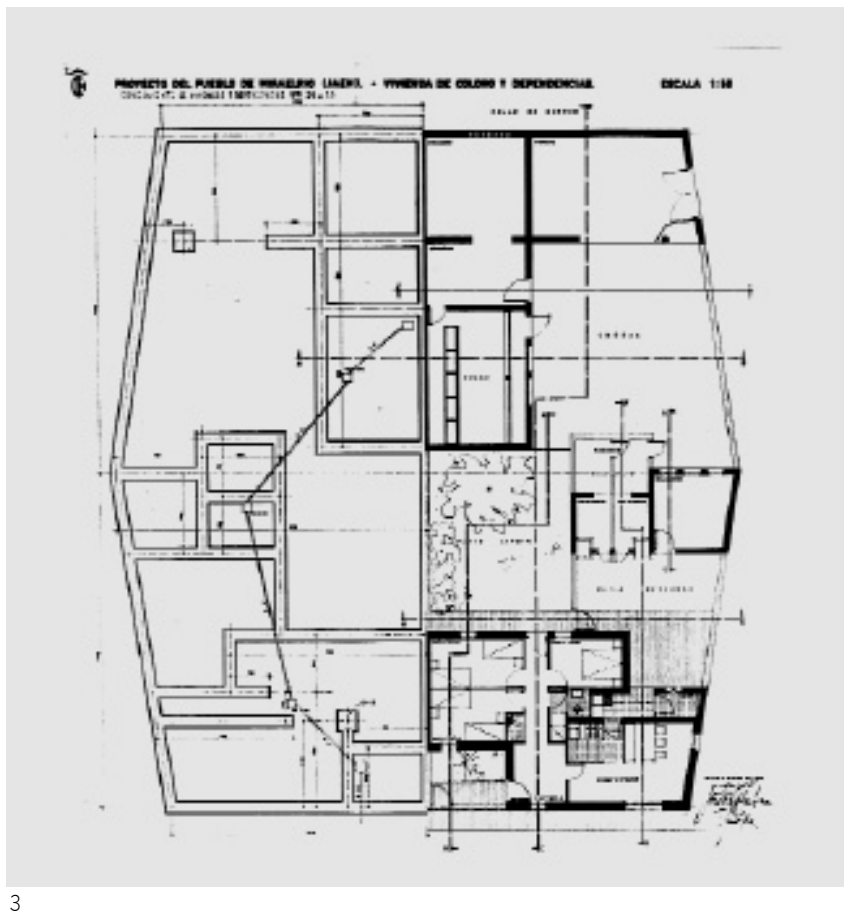

rias, carentes de autorreflexión y de todo proceso crítico, pero con las cuales se organiza la vida metropolitana actual". Y conocer los rasgos y procesos de nuestro mundo implica el hecho de que mirar a la ciudad hoy signifique lanzar la mirada mucho más allá, también físicamente, volver los ojos al medio rural como lugar de progreso.

En este marco, el papel de los territorios rurales resulta decisivo y la capacidad de la urbanística rural, la "ruralística", tal y como es definida en 1940 por Amos Edello, es incuestionable. Han pasado setenta años desde que Mussolini promoviera (1931-37) la ordenación de las "citta nuove": Littoria, Sabaudia, Pomezia, Aprilia y Pontinia en el territorio vecino a Roma del Agro Pontino con el fin declarado de "dar tierra a los campesinos, de crear un hombre nuevo, el hombre fascista antiurbano y antiobrero, ligado a la tierra y devoto del régimen, del cual es deudor de todo: casa, tierra, trabajo... bajo el control del partido".

Setenta años que permiten invertir completamente ese fin y observar el medio rural como un lugar capaz de evolucionar hacia estructuras cuyos objetivos de armonía con el medio natural y cooperación e integración social de sus habitantes lo conviertan en uno de los marcos más apetecibles del siglo XXI.

Hoy debemos ver las ciudades como los refugios de la solidaridad. (Jaime Lerner, alcalde de Curitiba.) 


Investigación
La arquitectura más allá
de las ciudades.
Presente y futuros
Ramón Pico Valimaña

\section{察}
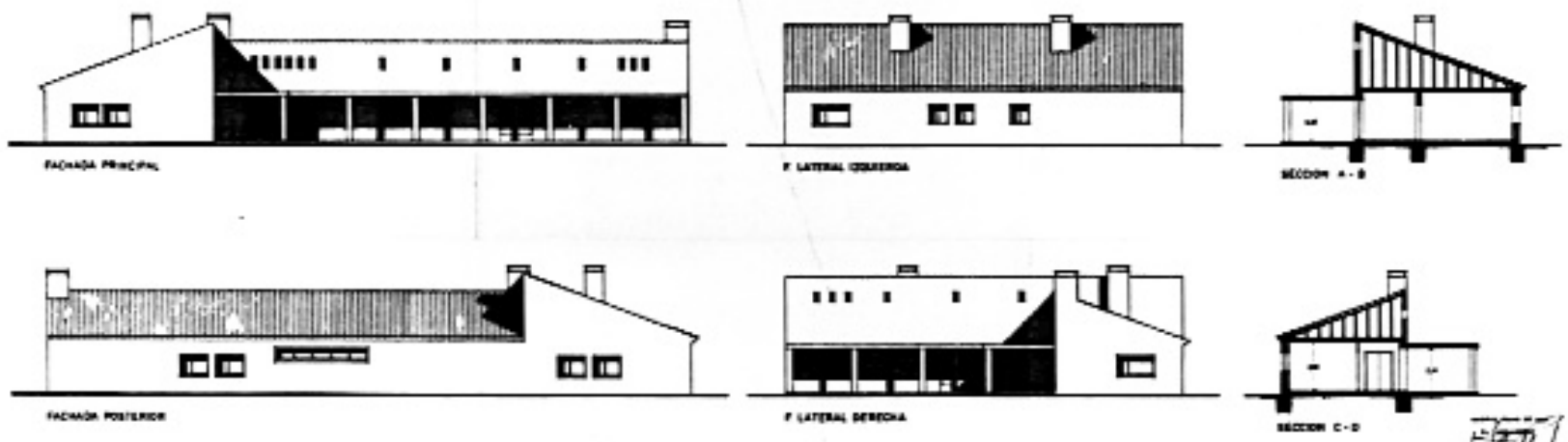

\section{Futuros. Mas allá de las ciudades}

No hay indicios de ciudades ni tecnología, pero intuyo formas de vida ahi abajo..

(Luke Skywalker, en El Imperio Contraataca.)

Desde su origen, los Poblados de Colonización cuentan, según mi opinión, con un valor fundamental: su capacidad de acuerdo entre condición moderna e interpretación de la tradición. Este hecho posibilita aprovechar sin prejuicios y con similar talante las bondades de las nuevas teorías y técnicas urbanísticas del momento junto a las de la cultura popular heredada.

Los poblados, ciudades aisladas y reproducidas en el espacio, se muestran como un medio urbano extraordinariamente eficaz, capaz de sintetizar necesidades hasta entonces contradictorias, estableciendo una coincidencia fértil y lúcida de las diversas demandas del pensamiento urbanístico contemporáneo: la inclusión de la naturaleza en la ciudad, la incorporación del trabajo a ésta, en definitiva, la acogida de la experiencia popular y la tradición.

Podemos encontrar una interesante experiencia en este sentido, cargada de posibilidades, en la formulación del Plan Estratégico de Jerez de la Frontera (Cádiz), un municipio cuyo extenso término municipal (141.000 has, uno de los mayores del país) acogió doce de los ciento doce poblados sobre los que el I.N.C. trabajó en Andalucia.

Su historia arranca en la década de los cuarenta. Con la intensificación del regadío, la demanda de mano de obra de las viñas y el empobrecimiento general del pais, especialmente en las zonas serranas, en estos años aumentaría considerablemente el número de jornaleros temporales en el término, desbordándose las posibilidades de alojamiento en los cortijos. Proliferaron así gran número de asentamientos en vías pecuarias, mediante la ocupación pacífica de éstas y en algunos casos, desarrollándose en torno a edificaciones que daban servicios a las mismas. Dichas edificaciones que comenzaron siendo chozas y teniendo un carácter exclusivamente temporal, con el tiempo, evolucionarían en cuanto a calidad, para ir adquiriendo carácter definitivo.

El I.N.C., ante las necesidades de alojar a esa población creciente en poblados donde la planificación fuera por delante de la espontaneidad, se propuso la creación de poblados no superiores a los 1.000 habitantes, atendiendo a criterios de proximidad a las tierras de cultivo y cercanía entre los poblados. Es así como comienza a poblarse de forma planificada el término municipal.

En algunos casos, cuando las dimensiones de las zonas colonizadas no suponían suficiente entidad que justificase un poblado, se recurría a edificaciones en diseminado. Hecho éste que ha servido para desarrollar en su entorno algún asentamiento espontáneo posterior.

Nos encontramos, pues, que frente a las construcciones que los grandes propietarios realizaban dentro de sus explotaciones y aquellas otras que el I.N.C. planificaba en las zonas que colonizaba mediante poblados o diseminados, surgen otras espontáneas y progresivas de muy distinto carácter, construidas por jornaleros que accedían de forma temporal a un trabajo agrícola.

El desarrollo de estos tres tipos de asentamientos (cortijos, poblados y espontáneos) hasta nuestros dias ha contribuido a la vertebración y ordenación del territorio rural jerezano. 
4 y 5. Miraelrío. Las construcciones administrativas centran el espacio público central

6. Planta de ordenación del Poblado de Esquivel (Alcalá del Río, Sevilla). Alejandro de la Sota, 1952-63

7. Entorno del Poblado de Doña Blanca (El Puerto de Santa María, Cádiz)

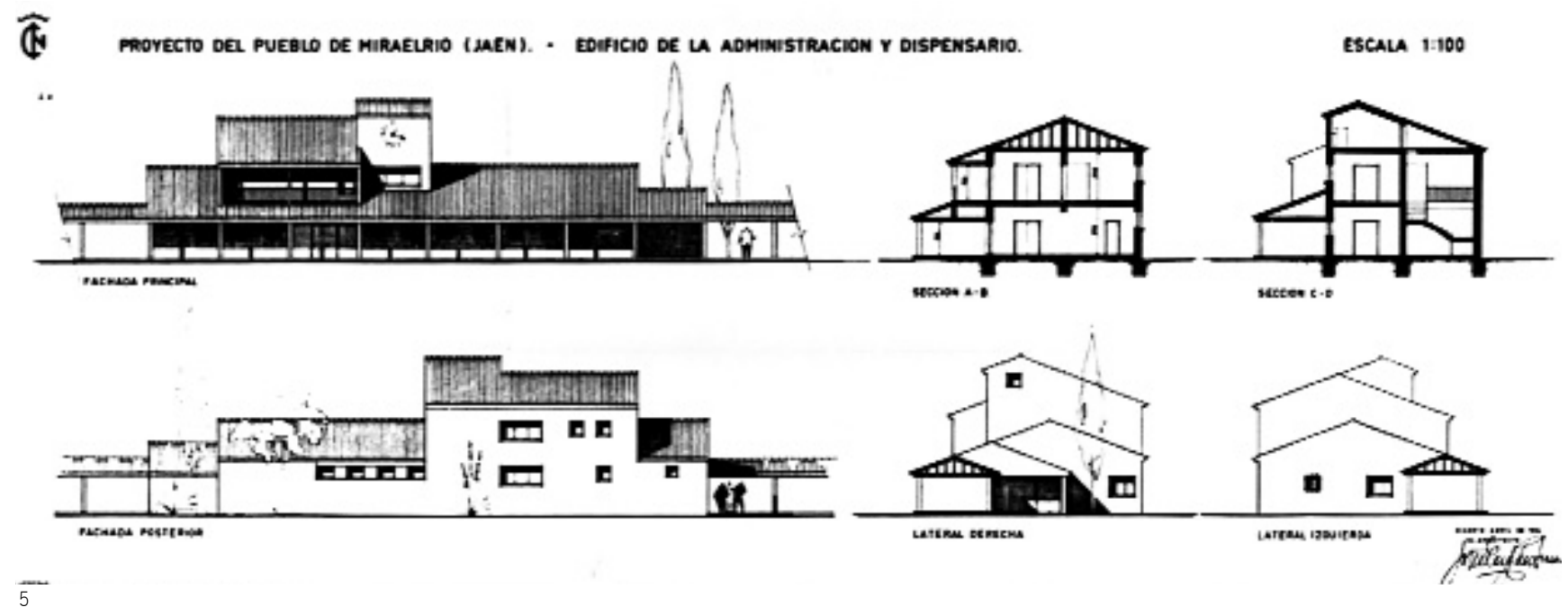

Merece la pena hacer hincapié en los objetivos que los urbanistas se han fijado para determinar los parámetros de ordenación de estos poblados. La Revisión del Plan General de 1995 establece que "El objetivo de esta normativa es el mantenimiento de la morfología urbana y de las tipologías actualmente existentes".

Pero la realidad de estos poblados en nuestros dias responde a otros datos que dejan obsoleta una normativa pensada para la cultura de "patria y tierra" de finales de los cuarenta. Es cierto que el uso de vivienda agrícola de las parcelas, en el origen de la actividad del Instituto Nacional de Colonización, obligaba a unas dimensiones generosas de las mismas: los aperos de labranza, partes de cosechas, pequeños huertos, carros, e incluso bestias, compartían la vida interior de las familias de los poblados.

Sin embargo, el propio I.N.C. cuestionó, en sus últimas actuaciones, este tipo de parcelación. Habían pasado dos décadas y el trabajo del campo, a raíz de la industrialización de los sesenta, se había visto completamente transformado. Quedaban sin sentido el "módulo carro" (origen de la distribución de los asentamientos en el territorio y la parcelación agrícola), las dobles circulaciones, los amplios corrales interiores, los cobertizos de las bestias o tractores (la maquinaria generalmente se arrendaba), e incluso los programas familiares.

Es importante observar cómo las amplias parcelas se han ido transformando en su interior. El espacio reservado para los animales va siendo ocupado por la descendencia y parentela de los primeros propietarios, prolongándose la edificación residencial en el interior de los corrales. El resultado es una suerte de par-

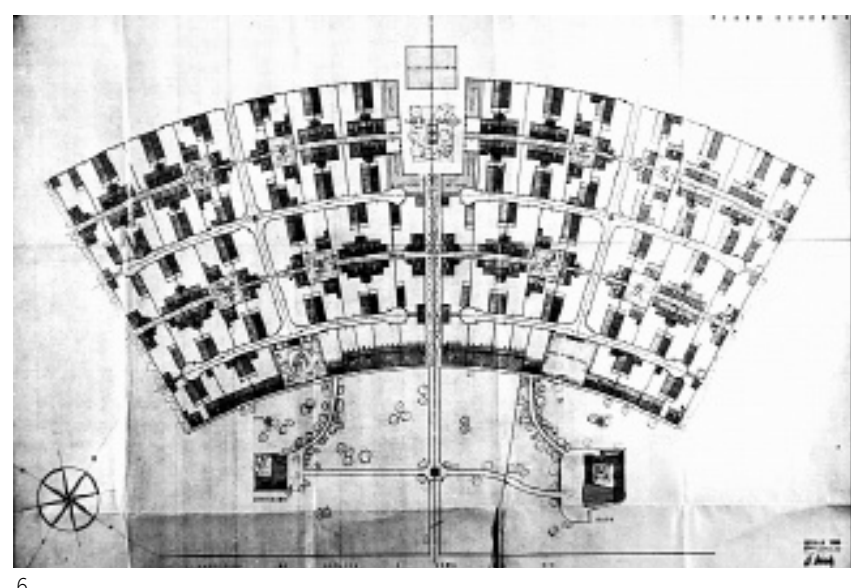
6

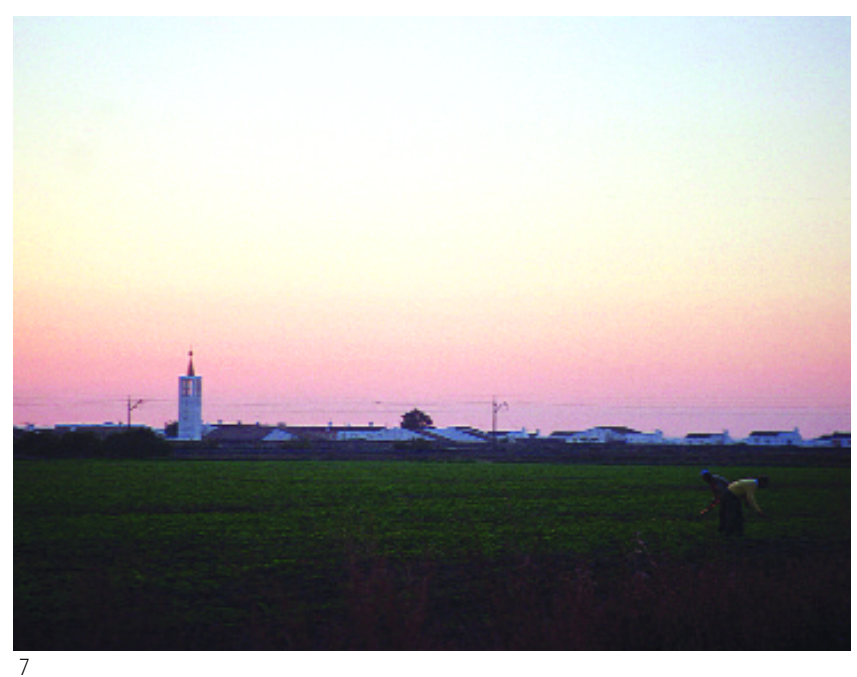




\section{Investigación}

La arquitectura más allá

de las ciudades.

Presente y futuros

\section{Ramón Pico Valimaña}

celas colectivas, a modo de condominios, en los que conviven dos o más unidades familiares compartiendo puerta y acceso. La realidad de la escasez de vivienda ha conducido a esta transformación, a la que el urbanismo y la arquitectura deben dar respuesta.

Por otra parte, han pasado ¡casi sesenta años!, y las transformaciones en la disciplina urbanistica y arquitectónica han sido notables. Hoy el discurso de la disciplina se orienta a dar respuesta mediante nuevas alternativas y sistemas a la sociedad de principios de siglo reconociendo sus valores de diversidad, movilidad, mestizaje, globalización, etc.

Las nuevas ideas urbanas pretenden en definitiva alcanzar espacios dotados de mayor flexibilidad y humanidad, en los que sea posible establecer nuevas relaciones entre la vivienda y el espacio público, e incluso entre las propias viviendas.

En esta línea, el futuro Plan Estratégico de la ciudad de Jerez, actualmente en redacción, apuesta por un modelo integrador y equilibrado entre el núcleo principal y los núcleos rurales, identificando a la ciudad como JEREZ + NUR (un hecho simbólicamente importante) y buscando un modelo de integración territorial en el que
8. Distribución de entidades menores en el término municipal de Jerez de la Frontera

se articule una relación intensa entre el espacio urbano consolidado y un renovado espacio rural.

En este modelo se plantean cuestiones de absoluta actualidad y necesidad como la inversión del proceso de crecimiento extensivo del núcleo principal, apostando por la densificación de los núcleos menores; la apuesta por la vitalidad y el desarrollo del sector productivo agrícola; la definición y desarrollo de un sistema de uso público y libre que tiene como base la identificación de un paisaje y sus señas de identidad, que actúe como elemento articulador e integrador del resto de actividades del territorio; el desarrollo de una ciudad de redes, que facilite el acceso de toda la ciudadanía a las últimas tecnologías limpias de comunicación, y que garanticen el contacto y la información más allá de su entorno espacial inmediato (este hecho permitiria hacer realidad el sueño del teletrabajo y reducir los desplazamientos y sus "efectos colaterales": contaminación, accidentes, consumo energético, pérdida de tiempo y recursos, tensiones, etc., aunque el efecto "desmaterialización" que provoca debilita el factor de cohesión social); o cuestiones tan decisivas como la autogeneración de energía de los distintos asentamientos.

La ciudad-territorio se acerca.

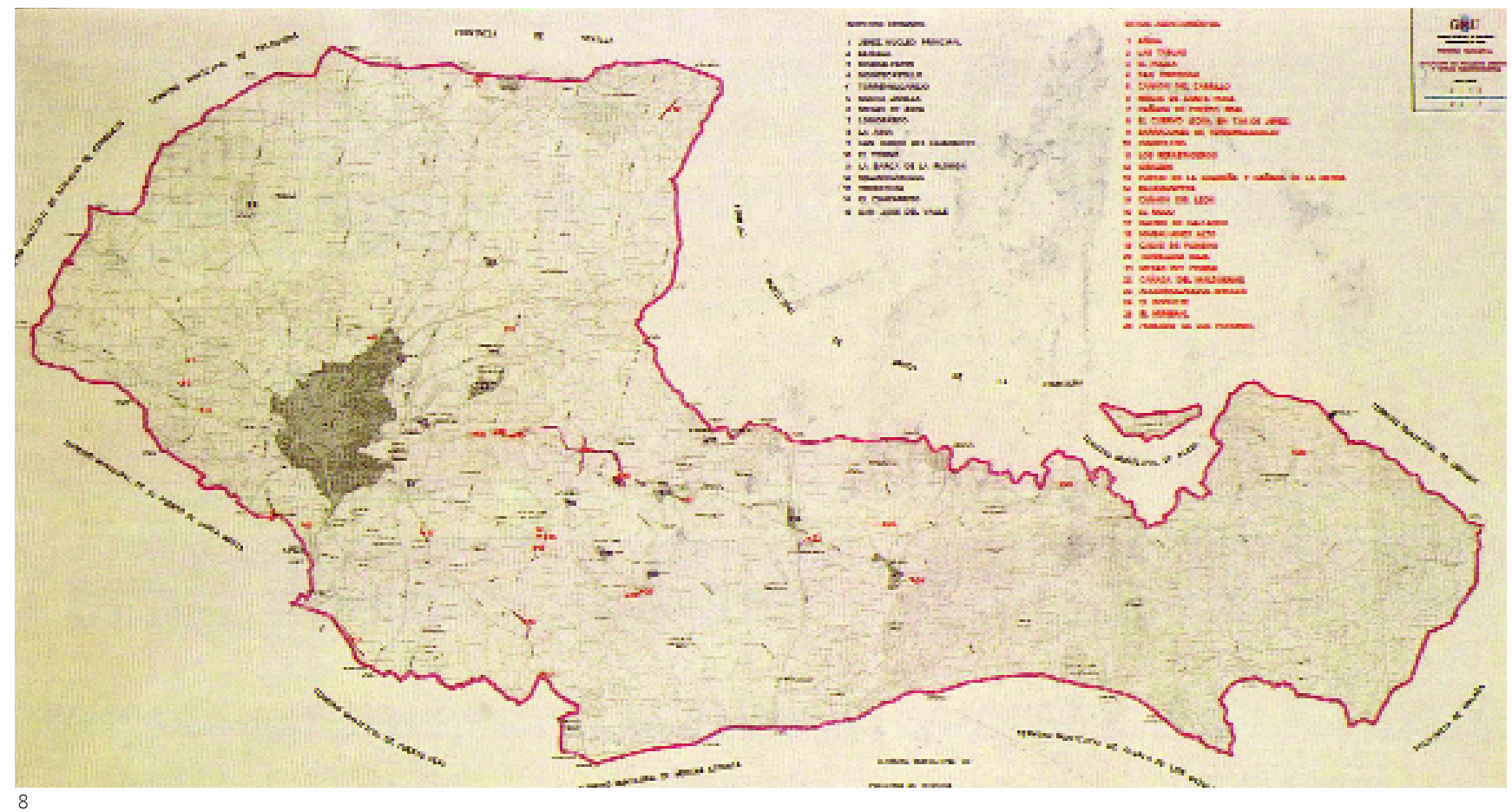

